\title{
How are Results Represented and Modified? Remarks on Jäger \& Blutner's Anti-Decomposition
}

\author{
Arnim von Stechow \\ University of Tübingen \\ arnim.stechow@uni-tuebingen.de
}

\begin{abstract}
The paper investigates a recent proposal to resultativity by G. Jäger and R. Blutner (J\&B). $J \& B$ say that the representation of result states of accomplishments by means of CAUSE and BECOME is not correct and should not be done in the syntax in terms of decomposition. They develop an axiomatic approach where each accomplishment/ achievement is related to its result by a particular axiom. Modification of the result by "again" makes use of these axioms and the restitutive/resultative ambiguity is a matter of lexical ambiguity or polysemy. They argue that the classical decomposition theory cannot treat the restitutive reading of "A Delaware settled in New Jersey again" (there had been Delawares in New Jersey but not this particular one; and those earlier Delawares never moved to New Jersey but were borne there). I discuss (and dispute) these data and compare the two theories. J\&B's contains an OT-part dealing with the disambiguating role of stress. While the decomposition theory cannot deal with the data mentioned, it can integrate the OTpart of J\&B's theory.
\end{abstract}

\section{Introduction}

In (Jäger and Blutner, 1999), Gerhard Jäger and Reinhard Blutner (henceforth J\&B) have launched a forceful attack against the account of the adverb wieder "again" I presented in (Stechow, 1995) and (Stechow, 1996). There I defended a classical account of the repetitive/restitutive ambiguity exhibited by the adverb wieder, which is very close to early proposals found in the Generative Semantics literature, notably (Morgan, 1969) and (McCawley, 1971). I argued that German surface syntax shows that something in the style of this old decomposition analysis must be correct.

One of the essential ideas of the decomposition theory in its classical form, which is due to (Dowty, 1979), is that the result state of an accomplishment or achievement verb is represented in its lexical entry directly as a predicate under a BECOME operator. If we want to modify the result with a functional adverb like again, then this adverb must apply to this embedded stative and must have narrow scope with respect to BECOME at some level of the representation. For instance, if the verb open has roughly the representation (1a), then the result modification by again must have the representation (1b), and the repetition of the action must have the analysis (1c):
(1)
a. $\lambda y \lambda x \cdot A C T(x)$ CAUSE BECOME(open(y))
b. $\lambda y \lambda x \cdot A C T(x)$ CAUSE BECOME(again open(y))
c. $\lambda y \lambda x \cdot \operatorname{again}(\operatorname{ACT}(\mathrm{x})$ CAUSE BECOME(open(y)))

Whereas (Dowty, 1979) says that again comes to be in the lower position through the application of a meaning postulate, I claimed that the decomposition of the verbal meaning must be visible in the syntax. That is the only difference. 
If I understand correctly, J\&B hold the view that this type of analysis is not right. They claim that the result-state information does not belong to the lexical entry of the verb. The entry of the verb open is simply a relation between the subject and an object (and an event). There is a RESULT functor that is defined via postulates for each verb. Adverbs operate on verbs modified by that operator. This is obviously an entirely different architecture, and it raises many questions about the representation of lexical information and about the syntaxmorphology interface. Unfortunately J\&B's theory is not worked out thoroughly enough to be fully assessed. Notably, it is not clear to me how modality could be implemented. But it is clear enough to comment on some detail.

On the following pages, I want to compare the decomposition analysis with J\&B's, and thereby acknowledge some of the weaknesses they raise of my approach. Partly, the criticisms levelled by J\&B can be overcome. In addition to the criticism, J\&B's paper has an independent part, namely an optimality theoretically based explanation of the disambiguation of certain ambiguities arising with wieder "again". I accept that part of the paper and I think it constitutes genuine progress in our understanding of functional adverbs.

The structure of this paper is as follows. In section 2, I report and discuss J\&B's criticism of my work. In section 3 and 4, I give an exposition of J\&B's theory. In section 5, I compare J\&B's approach with the decomposition approach. Section 6 reports the OT-part of their work. Section 7 carries the OT-principles over to decomposition theory. The final section contains the (non-) conclusion.

\section{J\&B's Arguments against Decomposition}

(Stechow, 1996) starts from the observation that the German sentence (2a) is ambiguous between a repetitive and a restitutive reading, whereas sentence $(2 \mathrm{~b})$ only has the repetitive reading.

(2) a. weil Fritz das Fenster wieder öffnete because Fritz the window again opened

b. weil Fritz wieder das Fenster öffnete because Fritz again the window opened

The explanation is that an accomplishment verb has the following syntactic structure, which for convenience is given in English:

(3) [voicep Fritz [voice CAUSE [vp BECOME [xp the window OPEN]]]]

At s-structure, the direct object moves to a Case-position AgrO above VoiceP, and the subject moves to AgrS. Thus, we have the following possible s-structures for (2a):

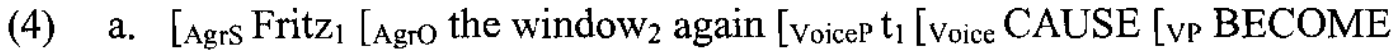
$\left[X t_{2}\right.$ OPEN]]]]] (repetitive)

b. [Agrs Fritz 1 [Agro the window 2 [voiceP $t_{1}$ [voice CAUSE [vp BECOME again $\left[x t_{2}\right.$ OPEN]]]] (restitutive)

The functional adverb again can attach to any syntactic projection to which its semantic application makes sense. If it appears to the right of the object, there are at least two possible positions which it might be occupying: the higher position indicated in (4a) or the lower position indicated in (4b). The former position is associated with the repetitive reading., i.e., 
on which the presupposition is that Fritz had already opened the window once in the past. The latter position is associated with the restitutive reading: the window is presupposed to have been open in the past, but neither Fritz nor anyone else need have opened it. Thus, the ambiguity of (2a) is simply a syntactic ambiguity and the explanation is in terms of operator scope. (2b), however, has only one possible syntactic analysis: again precedes the direct object and must therefore have wide scope with respect to the VoiceP "Fritz CAUSE..." and, therefore with respect to the CAUSE and BECOME operators. The only interpretation here is that the action is repeated. We need an appropriate semantics for the functors CAUSE and BECOME and again, of course. If we assume the semantics in (Dowty, 1979), CAUSE is interpreted as a chain of counterfactual dependencies, a relation between propositions. Then the causer must be analysed as "Fritz has some property". (Stechow, 1996) does it in slightly different way, but it really doesn't matter. BECOME can have Dowty's meaning, i.e., it denotes intervals that separate a false proposition from a true one, and $\operatorname{again}(p)(i)$ says that $p$ is true at the interval $i$ and it presupposes that $p$ is true at an $i^{\prime}$. where $i$ ' is either before $i$ or abuts $i$. We are assuming an intensional framework where propositions are sets of worlds and times.

These are the essentials of my account. The syntax is a bit abstract, but it fits neatly into what is done in current generative work (cf. e.g. (Kratzer, 1994), (Chomsky, 1995), (Rapp, 1997), (Marantz, 1997), (Ernst, 1998), and many others).

Let us come to J\&B's criticism of the theory now. They say that the account both overgenerates and undergenerates.

Here is an example for overgeneration:

John CAUSE again BECOME the window open [12]

J\&B correctly observe that there is a position between CAUSE and BECOME, and that presumably again should be able to take scope there, but it cannot, that is, the associated reading is claimed not to exist. This is an old problem, which already troubled Dowty in his early work on the problem. One can try to treat the problem syntactically. Most syntacticians assume that only one "light verb" is permitted above our XP. If both CAUSE and BECOME are in V, then no intermediate scope would be possible. This seems a reasonable solution. On the other hand, in (Stechow, 1996), I suggest that the reading in question might sometimes be available. Consider the scenario described by the following discourse:

(6) The window opened by itself. Mary closed it. John opened the window again.

The reading of the last sentence certainly can be represented as (5). Of course a representation with again under BECOME would do as well. But it seems to me that it is hard to argue that the reading (5) cannot exist at all.

Now we come to undergeneration. A criticism that I hear very often is that the theory cannot capture the restitutive/repetitive ambiguity exhibited by statives (Bierwisch, Frey \& Pittner). (Fabricius-Hansen, 1983) gives examples like these:
a. Der Kapitän ist WIEDER betrunken.
The captain is drunk again.
b. Der Kapitän ist wieder NÜCHTERN.
The captain is sober again.

In some sense, the first sentence expresses a repetition, the second one a restitution. I think, it is quite obvious what is going on here. In the first case, one period of drunkenness may follow the next one, we have an "abutting" scenario and might be quite annoyed with that. We could express this as one and the same state, but we do not. So one should not express the pre- 
supposed states in terms of maximality as I have done previously. The restitution in (7b) is triggered by the contrastive focus on the adjective. We oppose this to the alternative betrunken "drunk". So previous soberness must be separated by a non-soberness period. This is not directly expressed in the meaning of the adverb, but it is easily inferred.

Another putative case of undergeneration is (8). J\&B claim that this sentences, in which wieder precedes the direct object, can have a restitutive reading:

(8) weil Fritz wieder ein Fenster öffnet

My theory predicts that (8) should only have the repetitive reading, whereas it is easy to invent a story which triggers the restitutive reading. I accept this criticism. It is possible, however, to amend the approach, based on the fact that definite and indefinite objects must clearly be distinguished. We have to say that the structural accusative position is not above VoiceP. It is the nearest SpecXP under Voice, where Voice is filled by the an Agent-relation, here CAUSE in order to be close to J\&B. A related proposal is made in (Kratzer, 1994). The structure of the sentence would then be something like this:

(9)

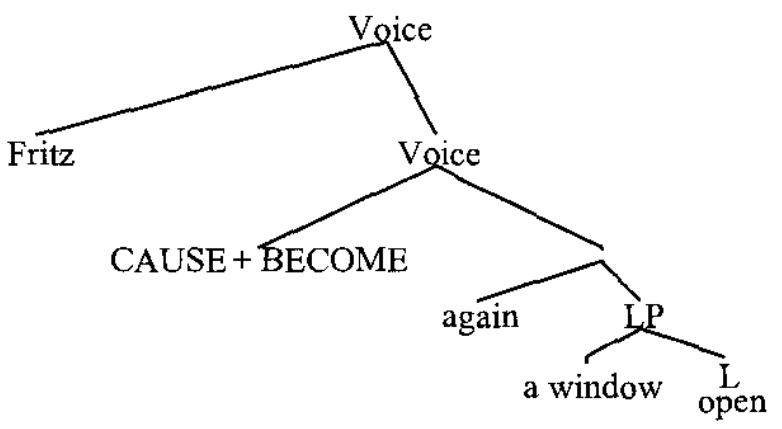

I have located the information CAUSE + BECOME in one node in order to meet the objection that there is no attachment site for again between CAUSE and BECOME. The interpretation would be achieved via functional composition. The notation $L$ for the "root" is in the spirit of Distributed Morphology (Halle and Marantz, 1993). In order to derive the word order effects for the interpretation, I have to assume that definite and in particular deictic terms scramble out of the VP; $\mathrm{cf}$. (Diesing, 1992). This has the consequence that wieder has scope over the entire VP whenever it precedes a definite term at s-structure. These changes do not affect the essentials of my version of the decomposition theory.

I have to add two caveats to the revised treatment. First we have to restrict the restricting property of the quantifier a window contextually. ${ }^{1}$ Otherwise the meaning of (9) would be too weak, because the sentence could be true if there were no window at the beginning of the opening process, but the process created an open one. This consequence of the meaning of BECOME is not addressed in the literature, and it might point at a serious weakness of the approach. $^{2}$

The most serious example of (an alleged) undergeneration is the following sentence:

A Delaware settled in New Jersey again. ${ }^{3}$

\footnotetext{
Perhaps by a property variable in the style of (Fintel, 1994).

See (Stechow, 1999).

I am not so sure whether this is a very suggestive example. The original sentence that motivated J\&B's theory is the German sentence

Neuerdings haben sich wieder einige Delawaren in New Jersey angesiedelt/niedergelassen.
} 
J\&B claim that this sentence has the following restitutive reading: a Delaware settled in New Jersey (recently), but no Delaware had ever settled in New Jersey before, though Delawares once lived in New Jersey (before they were expelled). The scenario presupposes that Manitou or some other divinity created the Delawares in New Jersey.

I think that J\&B are correct in claiming that a decompositional approach of the sort outlined cannot account for the restitutive reading where the presupposition is that a Delaware lived in New Jersey. The reason is that we have a "control accomplishment" in the sentence. The only restitutive reading we can have is this:

\section{$\exists x[$ Delaware(x) \& settle(x) CAUSE BECOME(again in New Jersey(x))]}

Here, the particular settler must have been in New Jersey before; this is not what J\&B want. They want this:

(12) Content: A Delaware settled in New Jersey.

Presupposition: One Delaware or other had been in New Jersey before.

The prediction of J\&B's approach is that causative accomplishments/achievements always have the restitutive reading with an indefinite subject. ${ }^{4}$ In a discussion, G. Jäger gives the following example:

(13) weil sich in Polen wieder ein Kommunist zum Präsidenten hat wählen lassen because himself in Poland again a communist for president has elect let

The reading of interest is that on which there has been a communist president before, but he wasn't elected. I don't get that reading, and the restitutive readings are very hard to get in all similar cases. One of the reasons might be that it is difficult to imagine an example with a causative subject control accomplishment/achievement that is true without a repetition of the action. A plausible story might be the scenario of The Omega Man, where everyone has an eye sickness called EB. In this situation one might say perhaps:

\section{Jetzt hat sich wieder jemand geheilt ${ }^{5}$ \\ Now has himself again someone cured}

By curing himself, someone reestablished the state that someone is healthy. In order to enforce the reading wanted, we have to assume that the agent was born with EB, so no specific reading is possible. Still the sentence should be appropriate in that situation. According to my judgement, it is not possible to use the sentence in this scenario. So I have doubts that data like (10) really necessitate J\&B's theory. In many cases the reading claimed is not possible, and we should look for an explanation for why the reading is possible in some cases at all. We

\footnotetext{
4 The criticism carries over to transitive accomplishments like "to open" if they are analysed as verbs of object control. Suppose, this verb has the following decomposition structure:

(i) OPEN(x,y) CAUSE BECOME OPEN(y)

Here, OPEN would be a 2-place relation meaning that $x$ affects $y$ in a particular way, the opening way. This is the manner component of the action. OPEN describes the result. Restitutive again must have a position below BECOME. But then no non-specific reading for an indefinite object like a window would be possible, because this quantifier must bind both occurrences of $y$ and must therefore have wide scope with respect to BECOME. Thus, decomposition theory seems to predict that the rather plausible decomposition (i) is not possible.

5 The verbs of healing and their interaction with wieder have been analysed in (Kamp and Rossdeutscher, 1994). This approach contains axioms/meaning postulates as well, and it would be interesting to compare it with J\&B.
} 
might find a pragmatic explanation, i.e., the literal meaning doesn't describe the situation, but it is a good approximation of a true description.

In the following section, I want to investigate in more detail whether it is at all possible to express $\mathrm{J} \& \mathrm{~B}$ 's reading in a decomposition theory. We will see that for principled reasons the answer is no.

\section{J\&B on "again"}

$\mathrm{J} \& \mathrm{~B}$ say that again is lexically ambiguous between a repetitive and a restitutive adverb. Both apply to properties of events. The first one says that the property is instantiated by an event only if there was an event of the same type in the past. The second one says that the property is instantiated by an event if the result state of the event occurred in the past. In formal terms, their meanings are these:
a. AGAIN $_{\text {rep }}:=\lambda p \lambda$ e.p(e) : $\exists \mathrm{e}^{\prime}<\mathrm{e}\left(\operatorname{OBTAINS}\left(\mathrm{e}^{\prime}\right) \& \mathrm{p}\left(\mathrm{e}^{\prime}\right)\right)$
b. AGAIN $_{\text {rest }}=\lambda \mathrm{p} \lambda$ e.p(e) $: \exists \mathrm{s}<\mathrm{e}(\mathrm{OBTAINS}(\mathrm{s}) \& \operatorname{RESULT}(\mathrm{p})(\mathrm{s}))$

OBTAINS applies to a possible event/state and says that it is real, i.e., it occurs in the real world. In other words, J\&B assume possibilistic quantification in their system throughout. ${ }^{6}$ The intuitive reading of RESULT(p)(s) is "s is the result state of a p-event", or "in s the postconditions of a p-event hold". J\&B use the sign ":" in order to mark the presupposition of an expression. Actually, the variable e occurring in the presuppositions should be bound by the $\lambda$-operators. I will assume that this is intended.

One might object that the stipulation that AGAIN should be lexically ambiguous makes this theory less favorable then a scope account. I will not raise this objection, but I want to point to another problem: the underlying AGAIN predicates are only defined for properties of events, not of states. But wieder "again" should be defined for properties of states as well. I will comment on this point in the next section.

Recall that the theory is designed to derive reading (12) for sentence (10), which J\&B represent as (16) in their formal language:

$$
\begin{aligned}
& \exists \mathrm{e}[(\operatorname{OBTAINS}(\mathrm{e}) \& \exists \mathrm{x}(\operatorname{DELAWARE}(\mathrm{x}) \& \operatorname{SETTLE} \mathrm{IN}(\mathrm{e}, \mathrm{x}, \mathrm{NJ}))) \\
& \exists \mathrm{s}<\mathrm{e}(\operatorname{OBTAINS}(\mathrm{s}) \& \exists \mathrm{x}(\operatorname{DELAWARE}(\mathrm{y}) \& \operatorname{LIVE} \mathrm{IN}(\mathrm{s}, \mathrm{x}, \mathrm{NJ}))))]
\end{aligned}
$$

The task is to derive this from the LF that the two authors assume for sentence (10), which should the following formula ${ }^{7}$ :

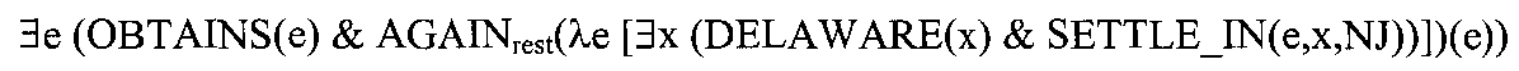

Inserting the definition of AGAIN $\mathrm{N}_{\text {rest }}$, we obtain:

$$
\begin{aligned}
& \exists e[(\operatorname{OBTAINS}(\mathrm{e}) \& \exists \mathrm{x}(\operatorname{DELAWARE}(\mathrm{x}) \& \operatorname{SETTLE} I \mathrm{IN}(\mathrm{e}, \mathrm{x}, \mathrm{NJ}))) \text { : } \\
& \exists \mathrm{s}<\mathrm{e}(\operatorname{OBTAINS}(\mathrm{s}) \& \operatorname{RESULT}(\lambda \mathrm{e}[\exists \mathrm{x}(\operatorname{DELAWARE}(\mathrm{x}) \& \operatorname{SETTLE} I N(\mathrm{e}, \mathrm{x}, \mathrm{NJ}))])(\mathrm{s}))]
\end{aligned}
$$

In order to derive (16) from (18), J\&B use the following theorem, which I will discuss in the next section but which we will take for true here.

A proper elaboration of J\&B's theory requires a possible worlds framework, I suppose.

There is no full LF for the sentence in the paper. I have deduced it from several pieces of calculation. 
Theorem 1: $\exists x(\mathrm{P}(\mathrm{x}) \& \operatorname{RESULT}(\mathrm{Q}(\mathrm{x}))(\mathrm{s})) \leftrightarrow \operatorname{RESULT}(\lambda \mathrm{e} \exists \mathrm{x}(\mathrm{P}(\mathrm{x}) \& \mathrm{Q}(\mathrm{x})(\mathrm{e})))(\mathrm{s})$

Furthermore, J\&B assume a meaning postulate whose content is that someone lives in some place iff he is in the result state of settling in that place:

(MP2) $\forall \mathrm{x} \forall \mathrm{y} \forall \mathrm{s}($ LIVE_IN(s,x,y) $\leftrightarrow$ RESULT(SETTLE_IN(x,y))(s))

At first glance, the postulate seems absurd. In the meaning under discussion, "settling in" implies "going/moving to". Certainly someone can live in some place without being an immigrant. He might be born there. In order to avoid this consequence, J\&B say that the event of bringing about the result might be merely a possible event. Furthermore, many possible events may have the same result state, for instance, the event that $\mathrm{x}$ is born in $\mathrm{y}, \mathrm{BORN}-\mathrm{IN}(\mathrm{e}$, $\mathrm{x}, \mathrm{y})$ would have the same result, i.e., J\&B should accept the following equivalence, if I understand them correctly:

$$
\text { RESULT(BORN_IN(x,y))(s) } \leftrightarrow \text { RESULT(SETTLE_IN(x,y))(s)) } \leftrightarrow \text { LIVE_IN(s,x,y) }
$$

For the time being we will not worry about this. We accept the theorem and the meaning postulate and can now easily show that (18) is equivalent with (16). Here is the proof:

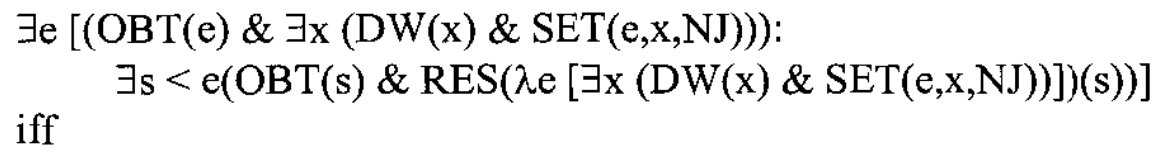

$\exists \mathrm{e}[(\mathrm{OBT}(\mathrm{e}) \& \exists \mathrm{x}(\mathrm{DW}(\mathrm{x}) \& \mathrm{SET}(\mathrm{e}, \mathrm{x}, \mathrm{NJ})))$ :

$$
\exists \mathrm{s}<\mathrm{e}(\mathrm{OBT}(\mathrm{s}) \& \exists \mathrm{x}(\mathrm{DW}(\mathrm{x}) \& \operatorname{RES}(\operatorname{SET}(\mathrm{x}, \mathrm{NJ}))(\mathrm{s}))] \quad \text { by THEOREM } 1
$$

iff

$\exists e[(O B T(e) \& \exists x(D W(x) \& \operatorname{SET}(e, x, N J)))$ :

$\exists \mathrm{s}<\mathrm{e}(\mathrm{OBT}(\mathrm{s}) \& \exists \mathrm{x}(\mathrm{DW}(\mathrm{x}) \& \operatorname{LIV}(\mathrm{x}, \mathrm{NJ}))(\mathrm{s}))] \quad$ by MP2

So J\&B have proved their point.

Note that the theory allows the subject of (10) to have a specific reading with respect to $\operatorname{again}_{\text {rest }}$, i.e., we can have the following Quantifying in-structure:

(20) $\exists$ e (OBTAINS(e) \& $\left.\exists x\left(\operatorname{DELAWARE}(\mathrm{x}) \& \operatorname{AGAIN}_{\text {rest }}(\lambda \mathrm{e}[\operatorname{SETTLE} I \mathrm{IN}(\mathrm{e}, \mathrm{x}, \mathrm{NJ})])(\mathrm{e})\right)\right)^{8}$

This formula expresses the reading that a particular Delaware came back to New Jersey. And we can have the two parallel repetitive readings as well. We simply have to choose $\mathrm{AGAIN}_{\text {rep }}$ instead of $\mathrm{AGAIN}_{\text {rest. }}$. All this looks rather attractive so far, and friends of logical deduction will be quite pleased that the desired consequences come out so nicely. But logical syntax needs semantic justification. So let us investigate J\&B's model theory, where the notion of RESULT, which is crucial for the approach, is interpreted.

If we compare this account with the decomposition approach, we see that the essential difference is in terms of the concept of result: the result generated by a CAUSE + BECOME-

\footnotetext{
8 This is the derivation of the restitutive reading:iui $\operatorname{AGAIN}_{\text {rest }}(\lambda \mathrm{e} . \mathrm{SETTLE} I \mathrm{IN}(\mathrm{e}, \mathrm{x}, \mathrm{NJ}))(\mathrm{e})$

$\leftrightarrow$ SETTLE IN(e,x,NJ) : $\exists$ s $<$ e(OBTAINS(s) \& RESULT $(\lambda$ e.SETTLE IN $(e, x, N J))(s))$ (meaning of $A_{\text {AGANN }}$ rest $)$

$\leftrightarrow$ SETTLE_IN(e,x,NJ) : $\exists s<e(O B T A I N S(s) \&$ SETTLE_IN(s,x,NJ))

(MP2)

Quantifying in the indefinite term yields:

$\exists x\left(D E L A W A R E(x) \& \operatorname{AGAIN}_{\text {rest }}\left(\lambda e . S E T T L E \_I N(e, x, N J)\right)(e)\right)$

$\leftrightarrow \exists x(D E L A W A R E(x) \&$ SETTLE_IN(e,x,NJ) : $\exists s<e(O B T A I N S(s) \&$ SETTLE_IN(s,x,NJ)))
} 
verb is much stronger. If a door was closed by John, then the decomposition approach says that that door was closed thereafter. J\&B say, however, that if a door was closed by John, then some door was closed thereafter. And if some Delaware came to New Jersey, the decomposition theory says that this Delaware was in New Jersey thereafter. J\&B say that some Delaware was in New Jersey thereafter. It is clear then that we cannot obtain J\&B's result by the classical method. For convenience, I give the decomposition LF for the sentence in its restitutive reading, where $\mathrm{s} *$ denotes the speech time.

\section{$\exists e<s^{*}(\exists x(D E L A W A R E(x) \& \operatorname{SETTLE}(e, x) \&$ CAUSE BECOME(AGAIN(LIVE_IN(x, NJ)))))}

Since AGAIN operates on the singular proposition LIVE_IN(x,NJ), we obtain the much stronger presupposition that $\mathrm{x}$ used to live in New Jersey in the past.

So is there a way to emulate J\&B's result in a decompositon approach? The answer is no. The reason is the following. ${ }^{9}$ An inspection of the formula (18) reveals an essential detail of J\&B's solution: the indefinite term a Delaware is analysed by two occurrences of the existential quantifier $\exists x$ (DELAWARE(x)... . So this is not a control structure, but a sort of sloppy-identity structure. The LF (17) shows that $A G A N_{\text {rest }}$ has wide scope with respect to the subject. If this were not so, the existential quantifier could not distribute to the presupposition. It is Theorem 1 that enables us to export the quantifier from the scope of RESULT in the content but to leave it there in the presupposition. But we can have a repetitive reading with AGAIN $_{\text {rep }}$ in the same position. This means that it is essential for the approach that again is lexically ambiguous. In a decomposition theory the two readings are represented by a difference in scope. But it is not possible to have a restitutive reading for an again that has scope over the subject of a causative verb, because that scope position would automatically give rise to a repetitive reading.

Recall that (Dowty, 1979) wants to combine a decompositional approach with a restitutive again that has wide scope with respect to the subject in the syntax. He has a meaning postulate that interprets this again as if it were under the scope of BECOME. (Zimmermann, 1993) and (Zimmermann, 1999) have argued that Dowty's postulate is not sound. My approach was designed to overcome these theoretical shortcomings and to correlate the surface position of again with the possible interpretations.

One appealing way of attempting to obtain J\&B's reading would be to move the subject across the board and to interpret the trace as a variable of the quantifier type $Q$ :
a Delaware $\lambda \mathrm{Q}[\mathrm{Q}(\lambda \mathrm{x}$. settle-in(NJ)) CAUSE BECOME$(\mathrm{Q}(\lambda \mathrm{x}$. again in(NJ)) $)]$ $=\mathrm{a}$ Delaware $(\lambda x \cdot \operatorname{settle}-\mathrm{in}(\mathrm{NJ}))$ CAUSE BECOME$($ a Delaware $(\lambda \mathrm{x}$.again in(NJ)) $)]$

This won't work, because the meaning is too weak. The formula would be satisfied in a scenario in which some Delaware caused other Delawares to settle in New Jersey again. Intuitively, however, sentence (10) doesn't have that reading. The conclusion is that the reading J\&B want for (10) cannot be represented in a decomposition approach.

A case for lexical ambiguity might be made by pointing out that there are adverbs that express only the restitutive or only the repetitive reading. I am not aware of an adverb with the first property, but erneut is an adverb with the second property.

\section{Fritz erneut ein Fenster öffnete}

9 I thank Ede Zimmermann for helping me to clarify this point. 
Erneut means the same as again, but the sentence only has the repetitive reading. J\&B could express this by saying that the only lexical entry of erneut is AGAIN $_{\text {rep. }}{ }^{10}$ (Stechow, 1996) blocks this interpretation by the syntactic stipulation that erneut may not attach to the "root" LP.

\section{J\&B's Model Theory}

The technical part of J\&B's model theory is given in appendix A of their paper. Before I review its essentials, I want to say something about the intuitions that lead the authors to their proposal. At the beginning of their paper, J\&B discuss and reject an analysis of AGAIN in purely temporal terms. These are the critical meaning rules:
a. repetitive AGAIN: $\lambda p \lambda i . p(i): \exists j<i(p(j))$
b. restitutive AGAIN: $\lambda p \lambda$ i.p(i) $: \exists j<i(\operatorname{RESULT}(p)(j))$

Here, $\mathrm{i}$ and $\mathrm{j}$ are time intervals, and $\mathrm{p}$ is a set of time intervals or set of world-times intervals. We can ask then what the RESULT-function should be. J\&B write on this:

»The first idea that comes to mind is roughly the following: result(p) is the most specific proposition that is always true after an interval immediately following an interval where $p$ was true. This first attempt will not do, however. To derive the restitutive reading of (2) correctly, we have to demand that the result of "John opening the window" is "the window is open". After an event of John opening the window, it is certainly true that the window is open, but it is also truc that the window has been opened by John. So in the restitutive reading, (2) would presuppose that the window is open as a result of John opening it before, and thus the restitutive reading would coincide with the repetitive one."

(Jäger and Blutner, 1999: 10)

The observation is, then, that a pair $(\mathrm{p}, \mathrm{i})$ consisting of a temporal proposition and a time cannot determine the result $(r, j)$, where $r$ is temporal proposition as well and $j$ is a time immediately following $\mathrm{i}$. Anyone who has thought about these problems will immediately agree, I guess. So this is not really surprising. J\&B add the following comment:

$»$ We take this as an indication that an analysis of actions, states etc. in terms of world/time pairs is too extensional in a sense: even if two event types are extensionally equivalent at all indices their result states might still differ.«

That might be right, but the comment is not supported by the examples considered. On the contrary, in the preceding section we observed that many different actions must have exactly the same result for $J \& B .^{11}$

I would like to mention another problem that arises with this kind of semantics. Consider again the restitutive reading of sentence (10). If some Delaware or other settled in New

10 The modification of statives would require the "third" entry, viz. AGAIN ${ }_{\text {state }}$, which is introduced below.

11 In personal communication, G. Jäger told me this. The sentence (i) can be true without presupposing the statement (ii):

(i) John is again opening a door that is being opened

(ii) A door that was being opened was open

This argument needs to be elaborated. I don't even know how to render it in a consistent way. 
Jersey then this must be at least one particular person, say John Yellowhorse. Therefore, at the time $\mathrm{j}$ immediately following the time $\mathrm{i}$ of immigration, it is true that John Yellowhorse was in New Jersey. Therefore the sentence should presuppose that John Yellowhorse had been in New Jersey before j. But the sentence doesn't presuppose that. Call this the Problem of Existential Instantiation.

In order to overcome the first difficuity, J\&B recur to a Davidsonian approach, which is rejected in its classical form. Here are the reasons why. Take the meaning rules (24) and take $i$ as a variable for events, whereas $\mathrm{j}$ is a variable for events in the first rule and a variable for states in the second rule. As before, we have Theorem 1 and the postulate MP2. The restitutive reading of the sentence is now represented as:

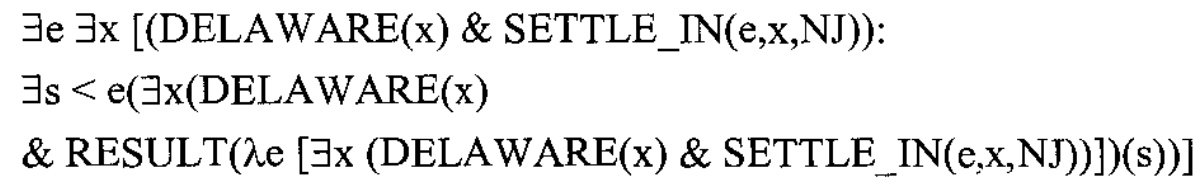

We have shown that the presupposition is equivalent to

$$
\exists x(\operatorname{DELAWARE}(\mathrm{x}) \text { \& LIVE_IN(x,NJ))(s)) }
$$

But this is not the only presupposition that we can derive from the presupposition in (25). $\mathrm{J} \& \mathrm{~B}$ point out that simple first order reasoning allows us to infer (27) from the presupposition in (25).

$$
\begin{aligned}
& \exists \mathrm{s}<\mathrm{e}\left(\operatorname { R E S U L T } \left(\lambda \mathrm{e} . \exists \mathrm{x}\left(\exists \mathrm{e}^{\prime}\left(\operatorname{DELAWARE}(\mathrm{x}) \& \operatorname{SETTLE} I \mathrm{IN}\left(\mathrm{e}^{\prime}, \mathrm{x}, \mathrm{NJ}\right)\right)\right.\right.\right. \\
& \& \text { SETTLE_IN(e, } x, N J)))(s))
\end{aligned}
$$

By Theorem 1 and MP2, this equivalent to

$$
\exists s^{<}<\mathrm{e}\left(\exists \mathrm{x}\left(\exists \mathrm{e}^{\prime}\left(\operatorname{DELAWARE}(\mathrm{x}) \& \operatorname{SETTLE} I \mathrm{IN}\left(\mathrm{e}^{\prime}, \mathrm{x}, \mathrm{NJ}\right)\right) \& \operatorname{LIVE} \mathrm{IN}(\mathrm{s}, \mathrm{x}, \mathrm{NJ})\right)\right)
$$

But this means that the Delaware the presupposition speaks about lives in New Jersey as a result of some settling event. This is precisely the presupposition the sentence should not have in its restitutive reading. Therefore the approach breaks down again. In order to rescue the proposal, J\&B say that events are not the usual events.

»Instead we propose to view events as pieces of pure information like states of affairs in situation semantics. They have participants, possibly temporal and local parameters and so on, but they may or may not obtain in reality. (A better term than just "event" might be "conceivable event"). Under this abstract notion of event, nothing is wrong with the claim that for every open window there is an event of this window being opened. Events that do take place in the world form a proper subset of the set of abstract events. They are in the extension of the predicate constant OBTAINS. (The same holds ceteris paribus for states.) «

(Jäger and Blutner, 1999: 12)

If I understand this correctly, J\&B want a Davidsonian approach with possible and actual events. The quantification is over possibilia and the predicate OBTAINS says that an event is real. Properties of result states like "living in" or "being open" are generated by events, but these events are merely possible, not real. These possible events have all the properties actual events have and they occur in time, because time is a notion is derived from them (Jäger and Blutner, 1999: fn. 8). But they need not be parts of the real world. 
Let us look at the details of J\&B's model theory. In view of their discussion, we expect an intensional framework. But we are deceived. The model proposed is entirely extensional. ${ }^{12}$ We have three sorts of things, individuals (D), states (S) and events (E). For events and states we have the usual relations temporal overlap $(\mathrm{O})$, temporal inclusion $(\subseteq)$, abutness $(><)$ and the like. The language should be typed, but the authors are not interested in too many details. $^{13}$

The model provides a relation $\mathrm{R}$ between events and states, that satisfies the following restriction, which I call Axiom 1:

$$
\text { Axiom 1: } \forall \mathrm{e} \exists \mathrm{s}(\mathrm{e}><\mathrm{s} \& \mathrm{eRs})
$$

This should be read as: "Every event abuts a state in which its post-conditions hold". In isolation, this condition is almost entirely trivial, because it neither characterises events nor does it describe their result states. The only information that can be read from the condition is that events have abutting states, but we don't know what $\mathrm{R}$ should be. This $\mathrm{R}$ is used to define the RESULT-function, a logical constant of the language. Thereby, $R$ gains a little more in the way of content.

(30) Axiom 2: $\forall \mathrm{s}: \mathrm{s} \in\|\operatorname{RESULT}(\phi)\|$ iff $\exists \mathrm{e}[\mathrm{eRs} \& \mathrm{e}><\mathrm{s} \& \mathrm{e} \in\|\phi\|], \phi$ a predicate of events.

(The name "Axiom 2" for the principle is my addition.) It is now very easy to prove Theorem 1 , which is repeated for convenience ${ }^{14}$ :

Theorem 1: $\exists x(\mathrm{P}(\mathrm{x}) \& \operatorname{RESULT}(\mathrm{Q}(\mathrm{x}))(\mathrm{s})) \leftrightarrow \operatorname{RESULT}(\lambda \mathrm{e} \exists \mathrm{x}(\mathrm{P}(\mathrm{x}) \& \mathrm{Q}(\mathrm{x})(\mathrm{e})))(\mathrm{s})$

I omit the interpretation function $\|\ldots$.$\| in the following proof:$

$$
\begin{aligned}
& \exists \mathrm{x}(\mathrm{P}(\mathrm{x}) \& \operatorname{RESULT}(\mathrm{Q}(\mathrm{x}))(\mathrm{s})) \\
& \leftrightarrow \exists \mathrm{x}(\mathrm{P}(\mathrm{x}) \& \exists \mathrm{e}(\mathrm{eRs} \& \mathrm{e}><\mathrm{s} \& \mathrm{Q}(\mathrm{x})(\mathrm{e})) \\
& \leftrightarrow \exists \mathrm{e}(\mathrm{eRs} \& \mathrm{e}><\mathrm{s} \& \exists \mathrm{x}(\mathrm{P}(\mathrm{x}) \& \mathrm{Q}(\mathrm{x})(\mathrm{e})) \\
& \leftrightarrow \operatorname{RESULT}(\lambda \mathrm{e} \cdot \exists \mathrm{x}(\mathrm{P}(\mathrm{x}) \& \mathrm{Q}(\mathrm{x})(\mathrm{e}))(\mathrm{s})
\end{aligned}
$$

Axiom 2

Predicate Logic

Axiom 2

The proof crucially makes use of the commutativity of existential quantifiers. Therefore, we do not get the non-specific reading for a universal quantifier. In other words,

\footnotetext{
12 To give an idea of the difficulties, consider the one place predicate sad, which should be a relation between an individual and a state. In order to express modality, the sentence Fritz is sad should express the set worlds in which Fritz is sad. But what should that be? We are tempted to say, it is the set $\{w \mid \exists s[O B T A I N(w, s) \&$ $\mathrm{SAD}$ (Fritz, s)]\}. But what is $\mathrm{SAD}$ (Fritz, s)? Presumably a truth-value, and SAD is an absolute relation not depending on the world parameter. Then OBTAIN would encode Lewis' (1968) counterpart relation C and the relation I "lives in". I don't know whether J\&B have this in mind. And we have to see whether this procedure is compatible with standard modal logic. One of the issues to be investigated is whether it is enough to speak of counterparts of events and states. Usually, one has to speak about counterparts of individuals as well in such an approach. For a recent discussion of the theoretical problems, see (Kupffer, 1999).

I don't know how modality is expressed in this theory. I suppose that sentences must express sets of worlds and not truth-values as assumed by J\&B. But then the OBTAIN predicate must be relativised to worlds. I am not sure whether these changes are trivial.

${ }_{14}$ J\&B give a somewhat winded proof. The following proof shows that the theorem is a direct consequence of the axioms.
} 


$$
\forall \mathrm{x}[\mathrm{P}(\mathrm{x}) \rightarrow \operatorname{RESULT}(\mathrm{Q}(\mathrm{x}))(\mathrm{s})]
$$

is not equivalent to

$$
\operatorname{RESULT}(\lambda \mathrm{e} \forall \mathrm{x}[\mathrm{P}(\mathrm{x}) \rightarrow \mathrm{Q}(\mathrm{x})(\mathrm{e})])(\mathrm{s})
$$

This is a welcome result, because the sentence

(31) Recently, every Delaware settled in New Jersey again

does not presuppose that every Delaware used to live in New Jersey at some earlier time.

\section{Jäger \& Blutner \& Dowty}

It is instructive to compare the two different methods of representing result states. Decomposition theory in the style of (Dowty, 1979) represents result states in the lexical representation of the verb. Verbs with result states have the structure ....BECOME + Stative proposition. Different verbs of change have different stative predicates under BECOME. Result states are qualitatively described. I have always taken this to be the great advantage that this kind of theory has in comparison to theories that speak of the "the result of an event" simpliciter, a notion that doesn't make sense to me.

J\&B's theory is not so different in this respect, despite the appearance that the relation $\mathrm{R}$ seems to be exactly this vacuous notion. But this is not so. The qualitative description of the result of each particular verb of change is described by a meaning postulate. There are as many meaning postulates as transformative verbs. Roughly the following correspondence holds:

(32) a. Decomposition theory:

Lexical entry for settle-in:

$\lambda w^{\prime} \lambda t^{\prime}\left[\left[\lambda w \lambda t . S E T T L E \_N_{w t}(x, y)\right]\right.$ CAUSE $_{w^{\prime} t}\left[\lambda w \lambda t . B E C O M E_{w t}\right.$ $\left.\left.\lambda \mathrm{w} \lambda \mathrm{t} . L I V E \_\mathrm{N}_{\mathrm{wt}}(\mathrm{x}, \mathrm{y})\right]\right]$

b. J\&B:

Lexical entries: SETTLE_IN

Accompanying meaning postulate: RESULT(SETTLE_IN) $=$ LIVE_IN

We change the decomposition theory in the following way: (32a) is not anymore the lexical analysis for the transitive verb settle in. This verb is analysed as the two-place predicate SETTLE_IN, which is like J\&B's with the difference that it depends on world and time. We now add the following axiom:

(33) The SETTLE_IN-Axiom

$$
\begin{aligned}
& \forall \mathrm{w}^{\prime} \forall \mathrm{t}^{\prime} \forall \mathrm{x} \forall \mathrm{y}\left[[ \lambda \mathrm { w } \lambda \mathrm { t } . \mathrm { SETTLE } _ { \mathrm { I } } \mathrm { N } _ { \mathrm { wt } } ( \mathrm { x } , \mathrm { y } ) ] \operatorname { C A U S E } _ { \mathrm { w } } \mathrm { C } ^ { \prime } \left[\lambda \mathrm{w} \lambda \mathrm{t} \cdot \mathrm{BECOME}_{\mathrm{wt}}\right.\right. \\
& \left.\left.\lambda \mathrm{w} \lambda \mathrm{t} . \mathrm{LIVE} \mathrm{IN}_{\mathrm{wt}}(\mathrm{x}, \mathrm{y})\right]\right]
\end{aligned}
$$

Every model has to satisfy this axiom. Next, let us define a RESULT-operator for two-place predicates as input and two-place predicate as output. There are many similar operators, i.e., a proper definition should take care of polyadicity:

$$
\begin{aligned}
& \forall \mathrm{w}^{\prime} \forall \mathrm{t}^{\prime} \forall \mathrm{x} \forall \mathrm{y}[\operatorname{RESULT}(\mathrm{P})(\mathrm{Q})(\mathrm{w})(\mathrm{t})(\mathrm{y})(\mathrm{x}) \\
& \left.\leftrightarrow\left[\left[\lambda \mathrm{w} \lambda \mathrm{t} \cdot \mathrm{P}_{\mathrm{wt}}(\mathrm{x}, \mathrm{y})\right] \operatorname{CAUSE}_{\mathrm{w}^{\prime} \mathrm{t}^{\prime}}\left[\lambda \mathrm{w} \lambda \mathrm{t} \cdot \mathrm{BECOME}_{\mathrm{wt}} \lambda \mathrm{w} \lambda \mathrm{t} \cdot \mathrm{Q}_{\mathrm{wt}}(\mathrm{x}, \mathrm{y})\right]\right]\right]
\end{aligned}
$$


We are now in a position to define for restitutive adverbs again (verbs of other valencies require further definitions). Each of these must have a transitive predicate as an argument in order to recover the result-state of the property. If the predicate is saturated, we cannot recover the result property anymore. The other arguments must consist of subject and object. These can be arguments of the individual type or of the quantifier type.

(35) The meanings restitutive of again

a. $\|$ again $^{1} \|_{w t}(P)(y)(x)$ iff $P_{w t}(y)(x)=1: \exists t^{\prime}<t\left[\operatorname{RESULT}(P)_{w t}(y)(x)=1\right]$

b. $\|$ again $^{2} \|_{w t}(P)(Q)(x)=1$ iff $Q_{w t}\left(\lambda w \lambda t \lambda y . P_{w t}(y)(x)\right)=1$ :

$\exists \mathrm{t}^{\prime}<\mathrm{t}\left[\mathrm{Q}_{\mathrm{wt}}\left(\lambda \mathrm{w} \lambda \mathrm{t} \lambda \mathrm{y} \cdot \operatorname{RESULT}(\mathrm{P})_{\mathrm{wt}}(\mathrm{y})(\mathrm{x})\right)=1\right]$, Q a quantifier intension

c. $\|$ again $^{3} \|_{w t}(P)(y)(Q)=1$ iff $Q_{w t}\left(\lambda w \lambda t \lambda x . P_{w t}(y)(x)\right)=1$ :

$\exists t^{\prime}<t\left[Q_{w t}\left(\lambda w \lambda t \lambda y \cdot \operatorname{RESULT}(P)_{w t}(y)(x)\right)=1\right]$, Q a quantifier intension

d. $\|$ again $^{4} \|_{w t}(P)(Q)(R)=1$ iff $R_{w t}\left(\lambda w \lambda t \lambda x \cdot Q_{w t}\left(\lambda w \lambda t \lambda y \cdot P_{w t}(y)(x)\right)\right)=1$ :

$\left.\exists \mathrm{t} '<\mathrm{t}\left[\mathrm{R}_{\mathrm{wt}}\left(\lambda \mathrm{w} \lambda \mathrm{t} \lambda \mathrm{x} . \mathrm{Q}_{\mathrm{wt}} \cdot\left(\lambda \mathrm{w} \lambda \mathrm{t} \lambda \mathrm{y} \cdot \operatorname{RESULT}(\mathrm{P})_{\mathrm{wt}}(\mathrm{y})(\mathrm{x})\right)\right)\right)=1\right]$

$\mathrm{Q}, \mathrm{R}$ quantifier intensions

The unspecific restitutive reading of the sentence A Delaware settled in New Jersey again could now be represented as:

$$
\begin{aligned}
& \text { again }^{3}{ }_{w t}(\text { SETTLE_IN })(N . J .)\left(\lambda w \lambda \text { t. } \mathbf{a}_{w t} \text { Delaware }\right) \\
& \leftrightarrow \mathbf{a}_{\mathrm{wt}} \text { Delaware }\left(\lambda \mathrm{w} \lambda \mathrm{t} \lambda \mathrm{x} \text {.SETTLE_IN } \mathrm{wt}_{\mathrm{w}}\left(\mathrm{N}_{\mathrm{J}} \mathrm{J} .\right)(\mathrm{x})\right) \text { : } \\
& \exists \mathrm{t} \text { '<t }\left[\mathbf{a}_{\mathrm{wt}} \text {, Delaware }\left(\lambda \mathrm{w} \lambda \mathrm{t} \lambda \mathrm{y} . \operatorname{RESULT}(\mathrm{P})_{\mathrm{wt}}(\mathrm{N} . \mathrm{J} .)(\mathrm{x})\right)=1\right] \quad \text { Def. of again }{ }^{3} \\
& \leftrightarrow \exists x\left[\text { Delaware }_{\mathrm{wt}}(\mathrm{x}) \& \mathrm{SETTLE}_{-} \mathrm{N}_{\mathrm{wt}}(\mathrm{N} . J .)(\mathrm{x})\right): \exists \mathrm{t}^{\prime}<\mathrm{t}\left[\exists \mathrm{x}\left[\text { Delaware }_{\mathrm{wt}} \text { ( } \mathrm{x}\right) \&\right. \\
& \text { RESULT(SETTLE_IN) } \left.\left.\left.)_{\text {wt }}(\text { N.J. })(x)\right)=1\right]\right] \text { Def. of a } \\
& \leftrightarrow \exists x\left[\text { Delaware }_{\mathrm{wt}}(\mathrm{x}) \& \text { SETTLE_IN }_{\mathrm{wt}}(\mathrm{N} . J .)(\mathrm{x})\right): \exists \mathrm{t}^{\prime}<\mathrm{t}\left[\exists \mathrm { x } \left[\text { Delaware }_{\mathrm{wt}}(\mathrm{x}) \&\right.\right. \\
& \text { LIVE_IN }{ }_{w t} \text { '(N.J.)(x) = 1]] Def. of RESULT and SETTLE_IN-Axiom }
\end{aligned}
$$

This is the simulation of J\&B's theory in a classical framework. It is perhaps not as elegant as their proposal, but it is clear how modality works and it is compatible with Dowty's analysis of aspectual classes. There is a proliferation of polysemy and syntactic types. But J\&B have to assume more ambiguity as well, it seems to me. Their AGAIN operates on properties of events only, but again can modify statives, as the examples in

(7) show. Let us call this third again AGAIN ${ }_{\text {state. }}$ In J\&B's theory, the meaning of this adverb should be this:

$$
\operatorname{AGAIN}_{\text {state }}:=\lambda \mathrm{p} \lambda \mathrm{s}\left[\mathrm{p}(\mathrm{s}): \exists \mathrm{s}^{\prime}<\mathrm{s}\left(\mathrm{OBTAINS}^{\prime}\left(\mathrm{s}^{\prime}\right) \& \mathrm{p}\left(\mathrm{s}^{\prime}\right)\right)\right]
$$

So there is much room for ambiguity here. While this section has shown that we can simulate J\&B's approach in a classical approach, it has not been shown that this is the optimal account. I would like to finish this paragraph by recalling you the problem of lexical variation. All achievements/accomplishments have result states, since all allow the formation of an adjectival passive. But not all of these verbs have a restitutive reading for again for all speakers.

$$
\text { Maria putzte die Küche wieder. "Mary cleaned the kitchen again" }
$$

Some people don't obtain the restitutive reading for this sentence - I do get it. I can say that those speakers do not decompose the verb in the syntax and hence have no attachment site for 
the inner reading. The theory that applies again $_{\text {rest }}$ to the verb would have a problem here, because the result state of the verb clean is the property clean, which applies to the object and must be introduced by an appropriate axiom. J\&B make the strong empirical prediction that all transformative verbs exhibit the repetitive/restitutive ambiguity.

\section{Disambiguation by Word Order and Stress: Bi-directional OT}

One of the objections (Stechow, 1996) raised against an account of the different readings of again in terms of lexical ambiguity was that it had nothing to say to disambiguation effects achieved by word order. (Dowty, 1979: 253) observes that we only have the external (= repetitive) reading, when again occurs in sentence initial position.

Again John opened the door

Dowty concludes the difference in readings must have a structural explanation, but his theory does not offer one because he assumes two meanings for again which are related by a meaning postulate. While (Stechow, 1996) gives a structural explanation for this particular example, I had nothing to say there about the disambiguating effect of the accent.

\section{a. Hans das Fenster wieder öffnete}

b. Hans das Fenster wieder öffnete

(40a) can only have the repetitive reading, and (40b) can only express a restitution. J\&B formulate OT (OT = Optimality Theory) principles that derive these facts. While I am not yet convinced by their axiomatic approach to resultativity, I believe that the OT part of the paper is on the right track, and there is genuine progress in our understanding of language here. In this section I present \& B's OT principles and show their impressing predictive power. In the next section I try to carry over the principles to Decomposition Theory. J\&B assume the following constraints.

DS: Definites scramble (out of the VP)

SC: Surface word order mirrors scope relations

DOAP: Don't overlook anaphorical possibilities ("Given constituents are de-accented")

GIVEN: De-accented constituents are given

Principle DS is attributed to (Reis, 1987) and it is stated as well in (Diesing, 1992). SC is folklore at least among semanticists, but I am not aware that this principle has been stated explicitly within an OT-approach. DOAP should be read as indicated in the parenthesis; J\&B claim that this interpretation can be subsumed under the more general formulation DOAP, which is due to (Williams, 1997). GIVEN, finally, is attributed to (Schwarzschild, 1999) ${ }^{15}$. Taken together, the prínciples DOAP and GIVEN form a biconditional, something is given if

\footnotetext{
15 It is not straightforward to compare J\&B's theory with that of Schwarzschild. Schwarzschild's concepts are rather different, for he speaks mostly of F-marking, not of accenting. His principles are: GIVEN: A constituent that is not F-marked is given; AVOID-F: Do not F-mark; FOC: A FOC-marked phrase contains an accent (where a phrase is FOC-marked iff its F-maker is not immediately dominated by another F-marker); HEADARG: A head is less prominent then its internal argument. The ranking is GIVEN $\cong F O C \gg A V O I D F>H E A D A R G$.
} 
and only if it is decaccented. ${ }^{16}$ We will see how these principles must be applied in concrete cases.

The ranking of the constraints is this:

$$
\mathrm{SC}>\mathrm{DOAP} \cong \mathrm{DS}>\mathrm{GIVEN}
$$

Standard OT has an input, an output and an evaluation procedure that says which is the best output. Here, the input is a phonetic form $\pi$ and the output is a proposition $\lambda$ or perhaps an LF denoting $\lambda$. The OT assumed by J\&B is bi-directional. One direction assumes that a phonetic form is the input and propositions are the output. The other direction assumes that a proposition is the input and phonetic forms are the output. The technical definition is this:

\section{Bidirectional Optimality \\ (Jäger and Blutner, 1999: 17)}

$(\pi, \lambda)$ is optimal iff

1. $(\pi, \lambda) \in$ GEN (i.e., both are well-formed),

2. there is no optimal $\left(\pi^{\prime}, \lambda\right) \in$ GEN such that $\left(\pi^{\prime}, \lambda\right)<(\pi, \lambda)$, and

3. there is no optimal $\left(\pi, \lambda^{\prime}\right) \in \operatorname{GEN}$ such that $\left(\pi, \lambda^{\prime}\right)<(\pi, \lambda)$.

I understand it that condition 2 covers the case where some meaning or LF $\lambda$ is the input. ( $\pi$, $\lambda$ ) can only be optimal if there is no $\pi$ ' that expresses $\lambda$ in a more economical way. But this is not enough to guarantee the optimality of $(\pi, \lambda)$. $\pi$ could express another meaning $\lambda$ ' in a more economical way than it expresses $\lambda$. Then the pair $\left(\pi, \lambda^{\prime}\right)$ would be better than $(\pi, \lambda)$ and hence blocks it. Thus condition 3 covers the case in which $\pi$ serves as the input of the evaluation. I take it that $(\pi, \lambda)<(\pi, \lambda)$ means that the derivation of $\pi$ ' from $\lambda$ violates fewer constraints than the derivation of $\pi$ from $\lambda$. Similarly, $\left(\pi, \lambda^{\prime}\right)<(\pi, \lambda)$ means that the derivation of $\lambda$ ' from the input $\pi$ violates fewer constraints than the derivation of $\lambda$ from $\pi$.

Condition 2 and 3 use the notion of optimality that should be defined here, but it is not clear to me in what sense the definition can be a recursive one. So I will simply ignore the adjective optimal in the two conditions.

J\&B say nothing to the technical realisation of the theory. Normally, OT constraints concern the output or the input + output. No intermediate "abstract" structure is permitted. But precisely this seems to be required here. The OT-constraints operate neither on the PF $\pi$ nor on the LF $\lambda$, but on an intermediate structure like s-structure or Spell Out. It would seem then that the approach has to presuppose a derivation relating $\pi$ and $\lambda$. For OT this means that the input cannot be as simple as $J \& B$ assume, we have to consider this intermediate structure as well. This is not in the spirit of standard OT but I will assume that it is necessary for doing semantics.

In order to make the theory work, J\&B make the following assumptions for constituents in the scope of wieder "again":

(44) a. There is only one structural position of wieder. Like the negation this adverb separates the subject from the VP. If an object occurs in front of wieder, it is scrambled out of the VP.

b. The object of a VP in the scope of wieder "is given by the presupposition, no matter whether we take the repetitive or the restitutive reading". (p. 18)

\footnotetext{
16 There is a remark in J\&B's paper (p. 18) that I do not understand: "We restrict attention here to empty contexts, so one might expect that every stressed constituent violates this requirement." I would have thought that it is just the other way round. In an empty context nothing is said and therefore nothing is given.
} 
c. The verb of a VP in the scope of wieder "is always given under the repetitive reading, but never under the restitutive reading". (p. 19)

d. "The constituent "object + verb" ...is given in all repetitive but in no restitutive reading."

e. Every sentence has a default stress that is realised on VP. If the VP has an object, the accent is realised there. If a VP contains no stress, it is de-accented. In that particular case, the accent has a default realisation on the adverb, if there is one.

f. A VP can only be de-accented, if the object is not scambled.

Let me comment on the alleged unique position of wieder, however. (Stechow, 1996), (Stechow and Rapp, 2000) and (Ernst, 1998) hold the view that functional adverbs like wieder and fast "almost" can attach to any projection at which they can be interpreted. Consider, e.g., the following examples:

a. Wieder $/ *$ nicht stand das Signal auf Rot. Wieder hielt der Zug an. again/*not stood the signal on red. again stopped the train

b. weil wieder/*nicht das Signal auf Rot stand und wieder/nicht* der Zug anhieit. because again $/ *^{*}$ not the signal on red stood and again/not* the train stopped

The negation in (45a) is not possible at all, and in (45b) it can only have a contrastive meaning. It is not difficult to show that wieder has a wider distribution than (sentential) nicht. Werner Frey (p.c.) points out to me that the indefinites wer, was do not scramble in German, but wieder may precede was in a sentence with a specific restitutive reading.

(46) Fritz was wieder geÖFFnet hat

Fritz something again opened has

This points to the availability of the lower position for wieder. Note finally, that the assumption creates problems for the syntax in J\&B's crucial example (10), whose German counterpart would be the following sentence:

(47) weil sich wieder ein Delaware in New Jersey niedergelassen hat

because himself again a Delaware in New Jersey downsettled has

Either the subject is located within the VP or wieder attaches to S. The former option has consequences for the evaluation, because we would have to say something about the movement of the subject to a sentential initial position, Is it an instance of Scrambling? The principles governing stress assignment assumed by J\&B seem to be these: sentential stress is realised on the verb. If there is a direct object, the stress is realised there. If the VP is de-accented and we have a functional adverb, the sentential stress is realised on the adverb.

Many researchers hold the view that presuppositions are given, i.e., they are old stuff. Assuming the theory of (van der Sandt, 1992), presuppositions may even be thought as being given by the previous text. A decomposition approach could say that the material in the scope of wieder is given. In the syntax, a verb would be given if all of its semantic components (CAUSE + BECOME + L) are given. In J\&Bs theory, conditions (44b) and (44c) have a stipulative flair.

Let us look now how the theory evaluates the following pattern (J\&B's (6)): 
(48) a. Hans wieder das Fenster öffnete.

b. Hans wieder das Fenster öffnete.

c. Hans das Fenster wieder öffnete.

d. Hans das Fenster wieder öffnete.

Here are the OT-tableaux for (48) by J\&B.

Definite object

\begin{tabular}{|l|l|l|l|l|}
\multicolumn{5}{c}{ Repetitive reading } \\
\hline & SC & DOAP & DS & GIVEN \\
\hline$(48 \mathrm{a})$ & & $* *$ & $*$ & \\
\hline$(48 \mathrm{~b})$ & & & $*$ & \\
\hline$(48 \mathrm{c})$ & & $* *$ & & \\
\hline$(48 \mathrm{~d})$ & & $*$ & & \\
\hline
\end{tabular}

Restitutive reading
\begin{tabular}{|l|l|l|l|l|}
\hline & SC & DOAP & DS & GIVEN \\
\hline$(48 \mathrm{a})$ & & $*$ & $*$ & \\
\hline$(48 \mathrm{~b})$ & & & $*$ & $* *$ \\
\hline$(48 \mathrm{c})$ & & & & \\
\hline$(48 \mathrm{~d})$ & & & & $*$ \\
\hline
\end{tabular}

For the evaluation of the VP, the reader is referred to the next footnote. ${ }^{17}$ Like J\&B, I will use the abbreviations rep and rest for repetitive and restitutive reading, respectively. The shorts $n s$ and $w s$ will stand for wide and narrow scope, respectively. DOAP is violated twice in example (48a, rep), because both the VP and the object carry the sentential stress. In ( $48 \mathrm{~b}$, rep), the VP is de-accented and the default accent lies on wieder. So only DS is violated. (48c, rep) exhibits two violations of DOAP, because the verb is not de-accented and the VP cannot be deaccented, since there is no intact VP. (48d, rep) is like (48c, rep) with the difference that the verb is de-accented. So this is a better candidate. As usual, the arrows point to the optimal candidates.

In (48a, rest), the object is given and should be de-accented. So DOAP is violated. One would think that the missing accent on the verb violates GIVEN, but the verb is not deaccented, since VP is not de-accented. The situation is different in ( $48 \mathrm{~b}$, rest); the VP is deaccented and should therefore be given. But neither the verb nor the VP are given. Hence GIVEN is violated twice. (48c, rest) violates no constraint. (48d, rest) differs only in having the verb de-accented. Thus GIVEN is violated.

The evaluation goes like this. (48c, rest) blocks $(48 \mathrm{a} / \mathrm{b} / \mathrm{d}$, rest), because these express the same meaning in a less economical way. And it blocks $(48 \mathrm{c}$, rep), because this reading involves more costs. (48b, rep) and (48d, rep) are equally harmonic and block all the other candidates in the tableau, i.e., (48a/c rep). As a result we have that $(48 \mathrm{~b} / \mathrm{d})$ unambiguously express the repetitive reading while $(48 \mathrm{c})$ unambiguously expresses the restitutive reading. This is exactly the correct prediction.

Next consider the evaluation of the following pattern:

17 In an email of June 6, 2000, Gerhard Jäger writes (my translation from German [A.v.S.]):

1. Every sentence receives an accent.

2. A de-accented constituent receives no accent.

3. The accent of Head-Complement structures is realised in the complement.

4. The accent of a constituent is realised in its head.

For the purposes of GIVENess a phrase counts as de-accented only if it should bear an accent. In other words, DOAP is violated if a given phrase contains an accent. Being an adjunct, wieder receives no accent. Therefore wieder doesn't count as de-accented if - as in (6c) - it carries no accent. In (34b) the default accent would go to the verb. Since it is on wieder instead, the verb has to be counted as de-accented. 
(50) a. Hans wieder ein Fenster öffnete.[33a]

b. Hans wieder ein Fenster öffnete[33b]

c. Hans ein Fenster wieder öffnete[34a]

d. Hans ein Fenster wieder öffnete[34b]

We have to investigate four combinatorial possibilities: the indefinite object has wide or narrow scope with respect to wieder and the reading is repetitive or restitutive. Here are the tableaux offered by J\&B:

(51)

Indefinite object has narrow scope

Repetitive reading

$\Rightarrow$\begin{tabular}{|l|l|l|l|l|}
\hline & SC & DOAP & DS & GIVEN \\
\hline$(50 \mathrm{a})$ & & $* *$ & & \\
\hline$(50 \mathrm{~b})$ & & & & \\
\hline$(50 \mathrm{c})$ & $*$ & $* *$ & & \\
\hline$(50 \mathrm{~d})$ & $*$ & $*$ & & \\
\hline
\end{tabular}

(52) Indefinite object has wide scope

Repetitive reading

\begin{tabular}{|l|l|l|l|l|}
\hline & SC & DOAP & DS & GIVEN \\
\hline$(50 \mathrm{a})$ & $*$ & $* *$ & & \\
\hline$(50 \mathrm{~b})$ & $*$ & & & \\
\hline$(50 \mathrm{c})$ & & $* *$ & & \\
\hline$(50 \mathrm{~d})$ & & $*$ & & \\
\hline
\end{tabular}

Restitutive reading

$\Rightarrow$\begin{tabular}{|l|l|l|l|l|}
\hline & SC & DOAP & DS & GIVEN \\
\hline$(50 \mathrm{a})$ & & $*$ & & \\
\hline$(50 \mathrm{~b})$ & & & & $* *$ \\
\hline$(50 \mathrm{c})$ & $*$ & & & \\
\hline$(50 \mathrm{~d})$ & $*$ & & & $*$ \\
\hline
\end{tabular}

Restitutive reading

$\Rightarrow$\begin{tabular}{|l|l|l|l|l|}
\hline & SC & DOAP & DS & GIVEN \\
\hline$(50 \mathrm{a})$ & $*$ & $*$ & & \\
\hline$(50 \mathrm{~b})$ & $*$ & & & $* *$ \\
\hline$(50 \mathrm{c})$ & & & & \\
\hline$(50 \mathrm{~d})$ & & & & $*$ \\
\hline
\end{tabular}

That (50b, ns, rep) and (50c, ws, rest) are winning optimal candidates is obvious, because they do not violate any constraint. Note first that these block any other candidate in their tableaux. In other words, $(50 \mathrm{a} / \mathrm{c} / \mathrm{d}, \mathrm{ns}$, rep) and $(50 \mathrm{a} / \mathrm{b} / \mathrm{d}$, ws, rest) are ruled out. Furthermore, $(50 \mathrm{~b}, \mathrm{~ns}$, rep) blocks (50b, ns, rest), and (50c, ws, rest) blocks (50c, ws, rep). It is also clear that (50d, ws, rep) should be optimal because it is the best candidate in its tableau and there is no better $\mathrm{PF}$ that could block it. What comes as a surprise is that (50a, ns, rest) should be optimal, since there is a better candidate in its tableau, viz. (50b, ns, rest). But this candidate is blocked by $(50 \mathrm{~b}, \mathrm{~ns}, \mathrm{rep})$. On the other hand, nothing blocks $(50 \mathrm{a}, \mathrm{ns}$, rest), so this is an optimal $(\pi, \lambda)$ indeed.

Again these results are exactly as we want to have them. It is not so clear, however, whether the theory really predicts all these results for the picture may change if we widen the range of candidates in competition. Consider the following PF - LF pair:

\section{$(53$, ns, rest)}

weil Hans wieder ein Fenster öffnete

This candidate violates no constraint and should therefore block all the other PFs expressing (ns, rest). In particular, (50a, ns, rest) should be blocked. For J\&B, this is not a wanted result, because $(50 \mathrm{a}, \mathrm{ns}$, rest) is a prototypical counterexample against my theory. I don't want to exclude, however, that the theory can be improved so that this difficulty can be met.

I would like to end this section with a remark on Dowty's sentence (39). J\&B say nothing about English and we could re-rank the constraints. But we cannot explain restitutive/repetitive ambiguity structurally, because every variant of again applies to the entire VP. 
If the restitutive reading for (39) is never available - regardless what the stress pattern is $\mathrm{J} \& \mathrm{~B}$ seem to need an ad hoc constraint for again in Topic-position that excludes a repetitive reading.

\section{Decomposition and OT}

Let us try to carry over the OT-principles to a decomposition approach. Recall that my representation is something like the structure (9) with repetitive wieder above VoiceP. The tree is Bierwisch's Lexical Semantic Structure (LSS). ${ }^{18}$ The only difference to Bierwisch is that I have access to this structure in the syntax directly. The principles determining givenness are the following ones:

(54) a. An constituent is given iff the constituent or its trace is in the scope or wieder "again" at LSS.

b. A (phonological) verb is given, if all of its LSS-heads are given.

It follows that the verb öfnete is not given if wieder has narrow scope with respect to BECOME, but öffnete is given if wieder has wide scope with respect to CAUSE. In the first case, the LSS-heads BECOME and CAUSE are not in the scope of wieder. In the second case, they are. The technical details of this would have to be elaborated, but the approach is a step toward a semantic explanation of J\&B's stipulations.

Since my syntax has more docking positions for wieder, I have to compare more pairs of structures than do J\&B. We only consider sentences with a definite object and check first which candidates are best for the repetitive reading. The winners are marked by an arrow.

(55) The repetitive reading

a. Hans wieder das Fenster öffnete

aa. Hans CAUSE+BEC wieder das Fenster OPEN

ab. Hans $s_{2}$ wieder das Fenster $t_{2}$ CAUSE+BEC $t_{1}$ OPEN

b. Hans wieder das Fenster öffnete

ba. Hans CAUSE+BEC wieder das Fenster ${ }_{1}$ OPEN

bb. Hans ${ }_{2}$ wieder das Fenster $\mathrm{t}_{2} \mathrm{CAUSE}+\mathrm{BEC} \mathrm{t}_{1}$ OPEN $\Leftarrow$

c. Hans das Fenster wieder öffnete

ca. Hans $s_{2}$ das Fenster $t_{2}$ CAUSE+BEC wieder $t_{1}$ OPEN

cb. Hans ${ }_{2}$ das Fenster ${ }_{1}$ wieder $t_{2}$ CAUSE + BEC $t_{1}$ OPEN

d. Hans das Fenster wieder öffnete

da. Hans ${ }_{2}$ das Fenster $t_{1}$ CAUSE+BEC wieder $t_{1}$ OPEN

db. Hans $s_{2}$ das Fenster 1 wieder $\mathrm{t}_{2}$ CAUSE+BEC $\mathrm{t}_{1}$ OPEN $\Leftarrow$

There are more representations; for instance, wieder can have wide scope with respect to CAUSE and the object may remain in situ. This configuration would not change the result. The SS (55aa) is not compatible with an LF that gives us the repetitive reading, because wieder occupies the wrong position. I have subsumed this under the Scope Principle SC.

Next, consider the candidates for the restitutive reading:

18 (Bierwisch, 1983, 1996) 
(56) The restitutive reading

a. Hans wieder das Fenster öffnete [6]

aa. Hans CAUSE+BEC wieder das Fenster OPEN

ab. Hans ${ }_{2}$ wieder das Fenster $t_{1} t_{2}$ CAUSE+BEC $t_{1}$ OPEN

b. Hans wieder das Fenster öffnete

ba. Hans CAUSE+BEC wieder das Fenster OPEN

bb. Hans $s_{2}$ wieder das Fenster $t_{2}$ CAUSE+BEC $t_{1}$ OPEN

c. Hans das Fenster wieder öffnete

ca. Hans ${ }_{2}$ das Fenster ${ }_{1} t_{2}$ CAUSE+BEC wieder $t_{1}$ OPEN

cb. Hans $_{2}$ das Fenster $t_{2}$ CAUSE+BEC wieder $t_{1}$ OPEN $\Leftarrow$

d. Hans das Fenster wieder öffnete

da. Hans ${ }_{2}$ das Fenster $t_{2}$ CAUSE+BEC wieder $t_{1}$ OPEN

$\mathrm{db}$. Hans ${ }_{2}$ das Fenster ${ }_{1}$ wieder $t_{2}$ CAUSE+BEC $t_{1}$ OPEN

The candidate $(56 \mathrm{cb})$ is the most highly ranked, as is desired. An here are the evaluation tableaux.

Repetitive reading

\begin{tabular}{|l|l|l|l|l|}
\hline & SC & DOAP & DS & GIVEN \\
\hline$(55 \mathrm{aa})$ & $*$ & $* *$ & $*$ & \\
\hline$(55 \mathrm{ab})$ & $*$ & $* *$ & $*$ & \\
\hline$(55 \mathrm{ba})$ & $*$ & & $*$ & \\
\hline$(55 \mathrm{bb})$ & & & & \\
\hline$(55 \mathrm{ca})$ & $*$ & $* *$ & $*$ & \\
\hline$(55 \mathrm{cb})$ & & $* *$ & & \\
\hline$(55 \mathrm{da})$ & $*$ & & $*$ & \\
\hline$(55 \mathrm{db})$ & & & & \\
\hline
\end{tabular}

Restitutive reading

\begin{tabular}{|l|l|l|l|l|}
\hline & SC & DOAP & DS & GIVEN \\
\hline$(56 \mathrm{aa})$ & & $*$ & $*$ & \\
\hline$(56 \mathrm{ab})$ & $*$ & $*$ & & \\
\hline$(56 \mathrm{ba})$ & & & $*$ & $* *$ \\
\hline$(56 \mathrm{bb})$ & $*$ & & $*$ & $* *$ \\
\hline$(56 \mathrm{ca})$ & & & $*$ & \\
\hline$(56 \mathrm{cb})$ & & & & \\
\hline$(56 \mathrm{da})$ & & & & $* *$ \\
\hline$(56 \mathrm{db})$ & $*$ & & & $* *$ \\
\hline
\end{tabular}

In order to complete the comparison, we would have to consider the examples with an indefinite object as well. It should be clear, however, that we can simulate most of the results of $J \& B$ in the decomposition approach. And we have the same problem with sentence (50a, ns, rest). It cannot be marked as optimal with the restitutive reading and a narrow scope indefinite. For convenience, the sentence is repeated:
a. Hans wieder ein Fenster öffnete
$[(50 \mathrm{a})]$
b. Hans CAUSE+BEC wieder ein Fenster OPEN

The reading in question is expressed by the SS/LF (58b). This sentence violates DOAP, since the object is given and should therefore be de-accented. Furthermore, GIVEN is violated, because the verb is not given and must therefore carry an accent. As before, sentence $(53$, ns, rest) violates no constraints if it has the same SS. Therefore, this candidate should block the PF-LF-pair in (58b). J\&B.

Recall, however, that I cannot represent causative control verbs in the same way as 


\section{Conclusion}

The revision of the decomposition theory can be summarised as follows: we still distinguish several positions for the functional adverb wieder, the restitutive one under CAUSE+BECOME and one or several repetitive positions above CAUSE+BECOME. We have to assume that accusative can be assigned to the base position of the object. This done, the OT-part of J\&B can be integrated into the theory, notably the principles that account for the disambiguation of the different readings by means of stress. The decomposition theory has some intuitive appeal when we ask why a VP is entirely given under the repetitive reading, but not entirely under the restitutive reading. On the other hand, unspecific restitutive readings with subject control verbs cannot be obtained in a decomposition approach, as we have seen. We must assume that functional adverbs are lexically ambiguous if we accept these readings.

We have seen that J\&B's readings are often not available, and we would like to know why this is so. There remain empirical problems for both theories, notably sentence (48a).

It could turn out that the strategy to separate the result state information from the content of the verb is the correct one. The same strategy is pursued in (Kamp and Rossdeutscher, 1994); I didn't have the time to compare this approach with J\&B's account. From what I remember, the new data discussed by $J \& B$ cannot be treated by Kamp and Rossdeutscher. So what is the correct view? A it stands, the issue cannot be decided because J\&B's framework remains to be extended to cover a larger body of phenomena, notably intensional contexts.

\section{References}

Bierwisch, Manfred. (1983). Semantische und konzeptuelle Repräsentation lexikalischer Einheiten. In Untersuchungen zur Semantik, 61-99. Berlin: Akademie-Verlag.

(1996). Lexical Information from a Minimalist Point. In The role of economy principles in linguistic theory, ed. Chris Wilder. Berlin: Akademie Verlag.

Chomsky, Noam. (1995). The Minimalist Program. Cambridge, MA: MIT Press.

Diesing, Molly. (1992). Indefinites. Cambridge MA: MIT Press.

Dowty, David. (1979). Word Meaning and Montague Grammar: Synthese Language Library. Dordrecht: Reidel. Emst, Thomas. (1998). The Syntax of Adjuncts: Unpublished manuscript. New Brunswick: Rutgers University.

Fabricius-Hansen, C. (1983). Wieder éin wieder? Zur Semantik von wieder. In Meaning, Use, and Interpretation of Language, eds. R. Bäuerle, C. Schwarze and A.v. Stechow. Berlin: de Gruyter.

Fintel, Kai von. (1994). Restrictions on Quantifier Domains, University of Massachusetts, Amherst: Ph.D. Dissertation.

Halle, Morris, and Marantz, Alec. (1993). Distributed Morphology and the Pieces of Inflection. In The View from Building 20, eds. K. Hale and S.J. Keyser, 111 - 176. Cambridge, Mass.: MIT Press.

Jäger, Gerhard, and Blutner, Reinhart. (1999). Against Lexical Decomposition in Syntax. Paper presented at IATL, Haifa.

Kamp, Hans, and Rossdeutscher, Antje. (1994). DRS-Construction and Lexically Driven Inference. Theoretical Linguistics 20:166-235.

Kratzer, Angelika. (1994). The Event Argument and the Semantics of Voice: UMass, Amherst.

Kupffer, Manfred. (1999). Counterparts and Qualities, University of Konstanz. Unpublished Doctoral Dissertation.

Lewis, David. (1968). Counterpart Theory and Quantified Modal Logic. Journal of Philosophy 65:113 - 126.

Marantz, Alec. (1997). No escape from Syntax: Dont' try a morphological analysis in the privacy of your own lexicon: MIT.

McCawley, James D. (1971). Prelexical Syntax. Paper presented at Report on the 22nd Annual Round Table Meeting on Linguistics and Language Studies.

Morgan, J. (1969). On Arguing About Semantics. Papers in Linguistics 1:49-70.

Rapp, Irene. (1997). Partizipien und semantische Struktur: Studien zur deutschen Grammatik. Tübingen: Stauffenburg Verlag Brigitte Narr GmbH. 
Reis, Marga. (1987). Die Stellung der Verbargumente im Deutschen. Stilübungen zum Grammatik-Pragmatik Verhältnis. In Sprache und Pragmatik, ed. Inger Rosengren. Stockholm.

Schwarzschild, Roger. (1999). Giveness, Avoid F and other Constraints onf the Placement of Accent. Natural Language Semantics 13:87-138.

Stechow, Arnim von. (1995). Lexical Decomposition in Syntax. In Lexical Knowledge in the Organisation of Language, eds. Urs Egli, Peter E. Pause, Schwarze Christoph, Arnim von Stechow and Götz Wienold, 81-177. Amsterdam/ Philadelphia: Benjamins.

- (1996). The Different Readings of Wieder "Again": A Structural Account. Journal of Semantics 13:87138.

- (1999). Temporally Opaque Arguments. In Festschrift per Andrea Bonomi, ed. Bruno Cecchetto. Milano: To appear.

Stechow, Arnim von, and Rapp, Irene. (2000). Fast "Almost" and the Visibility Parameter for Functional Adverbs. Journal of Semantics 16:149-204.

van der Sandt, Rob. (1992). Presupposition Projection as Anaphora Resolution. Journal of Semantics 13:87-113. Williams, Edwin. (1997). Blocking and Anaphora. Linguistic Inquiry 28:577-628.

Zimmermann, Th.E. (1993). Zu Risiken und Nebenwirkungen von Bedeutungspostulaten. Linguistische Berichte 146:263-282.

(1999). Meaning Postulates and the Model-Theoretic Approach to Natural Language Semantics. Linguistics and Philosophy 22:529-561. 